\title{
Chronic inflammation and gastrointestinal cancer
}

\author{
Satoshi Ida',2, Masayuki Watanabe ${ }^{1}$, Hideo Baba ${ }^{2}$ \\ ${ }^{1}$ Department of Gastroenterological Surgery, Cancer Institute Hospital of Japanese Foundation for Cancer Research, Tokyo 135-8550, Japan. \\ ${ }^{2}$ Department of Gastroenterological Surgery, Graduate School of Medical Sciences, Kumamoto University, Kumamoto 860-8556, Japan.
}

Correspondence to: Dr. Masayuki Watanabe, Department of Gastroenterological Surgery, Cancer Institute Hospital of Japanese Foundation for Cancer Research, 3-8-31 Ariake, Koto-ku, Tokyo 135-8550, Japan. E-mail: masayuki.watanabe@jfcr.or.jp

\section{A B S T R A C T}

Chronic inflammation has been identified as an important risk factor in the development of the gastrointestinal (GI) tract cancers, and the underlying molecular mechanisms have been studied extensively. Chronic inflammation is able to trigger cellular events to promote malignant transformation of normal epithelial cells in the GI tract to cancer. Host inflammation responses in carcinogenesis are through multiple mechanisms such as reactive oxygen and nitration species from mononuclear phagocytes and leukocytes, immune response and pro-inflammatory cytokines. Nuclear factor- $\mathrm{\kappa B}(\mathrm{NF}-\mathrm{\kappa B})$ has been considered as the central mediator of the immune response. Activation of NF- $\mathrm{KB}$ by phosphorylation leads to translocation of NF- $\mathrm{KB}$ protein to the nucleus, and in turn regulates the transcription of several pro-inflammatory cytokines and chemokines. Furthermore, chronic inflammation creates an environment for genomic and epigenetic changes. In this review, we summarize the important molecular mechanisms that link chronic inflammation and GI tract cancer, including esophageal, gastric and colonic cancers, focusing on infective and noninfective agents such as gastroesophageal reflux disease, Helicobacter pylori gastritis and inflammatory bowel disease.

Key words: Cancer, gastrointestinal tract, immune response, inflammation

\section{Introduction}

It is now widely accepted that inadequately resolved chronic inflammation could increase cancer risk. The etiology of inflammation varies and could result from infection with viruses, bacteria or parasites. Alternatively, it may be noninfective but caused by a physical or chemical irritant. For example, hepatitis $\mathrm{B}$ and $\mathrm{C}$ viruses account for more than $80 \%$ of hepatocellular carcinoma cases in the world, while human papillomavirus infection is the leading cause of anogenital cancer, and Helicobacter pylori has been considered as the major cause of gastric adenocarcinoma and is known to significantly increase the risk of gastric mucosa-associated lymphoid tissue lymphoma. Moreover, there are numerous examples of noninfective agents being associated with inflammation and development of cancers. Several pathological conditions in the gastrointestinal (GI) tract such as gastroesophageal reflux disease (GERD), inflammatory bowel diseases (IBDs), chronic pancreatitis, and cholangitis-related cholangiocarcinoma illustrate this link. ${ }^{[1]}$ As a barrier to the environment and as the main organ system for digestion and absorption of food, the GI tract is exposed to many substances and stimulants.

\begin{tabular}{|l|l|}
\hline \multicolumn{2}{|c|}{ Access this article online } \\
\hline Quick Response Code: & Website: \\
\hline & www.jcmtjournal.com \\
\cline { 2 - 2 } & \\
\hline
\end{tabular}

Some of these, such as alcohol and acid, can cause GI cancers by linking to chronic inflammation [Table 1]. ${ }^{[2,3]}$ Thus, in this review, we discussed emerging concepts and provided specific examples for the role of chronic inflammation in the development of GI cancers, including esophageal, gastric and colonic cancers, since they have been investigated most thoroughly.

\section{Role of Chronic Inflammation in Cancer Development}

\section{Immune response and cytokines in cancers}

Chronic inflammation is characterized by the infiltration of mononuclear cells, such as macrophages, lymphocytes and plasma cells in damaged tissue, together with tissue destruction and attempts to repair. In this inflammatory state, local activation of the immune system occurs. Natural killer cells, monocytes, macrophages, dendritic cells, mast cells and granulocytes usually elicit the first immune response and initiate inflammation. Of the many cell types active during chronic inflammatory response,

This is an open access article distributed under the terms of the Creative Commons Attribution-NonCommercial-ShareAlike 3.0 License, which allows others to remix, tweak, and build upon the work non-commercially, as long as the author is credited and the new creations are licensed under the identical terms.

For reprints contact: reprints@ @medknow.com

How to cite this article: Ida S, Watanabe M, Baba H. Chronic inflammation and gastrointestinal cancer. J Cancer Metastasis Treat 2015;1:138-43.

Received: 27-07-2015; Accepted: 11-08-2015. 
Table 1: Gastrointestinal malignancies linked to chronic inflammation

\begin{tabular}{lll}
\hline Organ & Tumor type & Chronic inflammation \\
\hline Esophagus & Squamous cell carcinoma & Cigarette smoking, alcohol and hot beverages \\
& Adenocarcinoma & GERD \\
Stomach & Adenocarcinoma & H. pylori, autoimmune \\
& MALT lymphoma & H. pylori, HCV \\
Colorectal & Colorectal cancer & Ulcerative colitis, Crohn's disease \\
Liver & Hepatocellular carcinoma & HBV, HCV and cirrhosis (alcohol, NAFLD) \\
Pancreas & Pancreatic ductal adenocarcinoma & Chronic pancreatitis \\
Biliary system & Gallbladder carcinoma & Chronic cholecystitis \\
& Cholangiocarcinoma & PSC, chronic cholangitis and liver cirrhosis \\
\hline
\end{tabular}

GERD: Gastroesophageal reflux disease; H. pylori: Helicobacter pylori; HBV: Hepatitis B virus; HCV: Hepatitis C virus; NAFLD: Non-alcoholic fatty liver disease; PSC: Primary sclerosing cholangitis; MALT: Mucosa-associated lymphoid tissue

macrophages are one of the key players. ${ }^{[2]}$ Recent studies showed that tumor-associated macrophages (TAMs) were dispersed throughout tumor lesions and contributed to tumor growth, invasion and metastasis by producing various mediators. ${ }^{[4,5]}$ In general, TAMs are found within and surrounding most tumor cells and can, when activated, release numerous factors to influence the behavior of tumor cells and the local tissue microenvironment. Interferon (IFN)- $\gamma$ induces "classical" activation of macrophages, while anti-inflammatory mediators such as interleukin (IL)-10, IL-4 and IL-13 provoke "alternative" activation of macrophages, which are referred as M1 and M2 macrophages respectively. ${ }^{[6,7]}$ M2 macrophages are oriented toward promoting tumor progression, tissue repair and angiogenesis as well as suppressing adaptive immunity in tumors, whereas M1 macrophages, as classically or alternatively activated macrophages, are activated by lipopolysaccharides and IFN- $\gamma$, and can secrete high levels of IL-12 and low levels of IL-10. ${ }^{[4,8-10]}$

\section{Reactive oxygen species, nitric oxide and cyclooxygenase-2}

Chronic inflammation creates a microenvironment locally to induce genomic instability in cells. At the site of chronic inflammation, cells are exposed to oxygen and nitrogen radicals from mononuclear phagocytes and leukocytes. These radicals can cause DNA damage. For example, nitric oxide and its products may exert oncogenic effects via several mechanisms, including inhibition of DNA mismatch repair, protein damage, induction of hypermethylation, inhibition of apoptosis, mutation of DNA and disruption of cellular repair functions such as those involving the p53 pathway. ${ }^{[11-13]}$ Release of reactive oxygen and nitrogen species is enhanced by pro-inflammatory cytokines such as tumor necrosis factor (TNF), IL-1 $\beta$ and IFN- $\alpha$.

Another inducible enzyme with carcinogenic properties that is active in inflamed and malignant tissues is cyclooxygenase-2 (COX-2). Strong epidemiological evidence implicates that COX-2 plays a role in the pathogenesis of a number of epithelial malignancies, including esophageal, gastric and colorectal cancers (CRCs). Several mechanisms of COX-2mediated intestinal carcinogenesis have been elucidated. These include inhibition of apoptosis, modulation of cellular adhesion and motility, promotion of angiogenesis and immunosuppression. ${ }^{[14-16]}$ Among the most potent inducers of COX-2, there are key pro-inflammatory cytokines, IL- $1 \alpha$, IL- $1 \beta$ and TNF- $\alpha$. COX-2 is significantly overexpressed in malignancies, and non-steroidal anti-inflammatory drugs are associated with a reduction in the incidence of a variety of GI cancers. ${ }^{[17,18]}$

\section{Nuclear factor $-\kappa B$}

Inflammatory responses contribute to carcinogenesis through multiple mechanisms. As mentioned above, reactive oxygen species, $\mathrm{COX}-2$ and some cytokines interact with each other in a complex manner during development and progression of an inflammatory environment. One such mediator is the transcription factor nuclear factor- $\mathrm{\kappa B}(\mathrm{NF}-\kappa \mathrm{B})$, which is a key mediator of inflammation and involved in the regulation of apoptotic and oncogenic gene expression and activation. ${ }^{[19]} \mathrm{NF}-\kappa \mathrm{B}$ has often been described as the central mediator of the immune response and as being critically involved in cancer-associated inflammation and the tissue repair response. ${ }^{[2,20]}$ Aberrant activation of NF- $\kappa B$ protein was associated with inflammation and cancer in mouse models and in human GI cancers. ${ }^{[21-23]}$ Activation of NF- $\mathrm{KB}$ plays an important role in integrating multiple stress stimuli and regulating immune responses. ${ }^{[23,24]}$ Bile acids, particularly deoxycholic acid, have been shown to activate the NF- $\kappa B$ pathway. ${ }^{[25]} \mathrm{NF}-\kappa \mathrm{B}$ activation through phosphorylation leads to translocation into the nucleus, and in turn regulates the transcription of several pro-inflammatory cytokines such as TNF- $\alpha$, IL-1 $\beta$, IL-6, IL-8, and chemokines such as CXCL-1 and CXCL-2. ${ }^{[24,26]}$

Thus, chronic inflammation could lead to carcinogenesis by sustaining pro-inflammatory oncogenic signaling, angiogenesis and immune suppression.

\section{Esophageal Cancer}

There are two major histological subtypes of esophageal cancer, that is, esophageal squamous cell carcinoma 
(ESCC) and esophageal adenocarcinoma (EAC). Tobacco smoking and alcohol consumption are the two major risk factors in ESCC, ${ }^{[27]}$ with a risk of heavy smokers/drinkers for 50 times greater in the induction of ESCC. ${ }^{[28]}$ Tobacco smoking and alcohol consumption have been associated with the field of cancerization in the upper aerodigestive tract. For example, Oka et al. ${ }^{[29]}$ demonstrated that tobacco smoking was likely to induce global DNA hypomethylation and site-specific $\mathrm{CpG}$ island promoter hypermethylation in the normal-appearing esophageal mucosa. Both these mutations are representative of DNA methylation alterations occurring in cancer cells. In addition, we also previously reported that global DNA hypomethylation in normal esophageal mucosa was observed in ESCC patients who habitually smoked, ${ }^{[30]}$ suggesting epigenetic field defected after exposure to risk factors. Recently, deficiency in the enzyme aldehyde dehydrogenase 2 (ALDH2), which causes the so-called alcohol flushing response, has been revealed to increase the risk of alcohol-related ESCC. ${ }^{[31]}$ In East Asian populations, there is a variant of ALDH2 in which the glutamate at position 487 is replaced with lysine, resulting in an inactive protein. ${ }^{[32]}$ Consumption of hot beverages is also suspected to cause chronic inflammation in esophageal squamous cell mucosa. ${ }^{[33]}$ In addition, the influence of human papillomavirus in increasing ESCC risk is still under debate. ${ }^{[34]}$

Gastroesophageal reflux disease (GERD), cigarette smoking and obesity are all risk factors in EAC. ${ }^{[35]}$ EAC develops through chronic exposure to gastroesophageal reflux, Barrett's esophagus, dysplasia and adenocarcinoma as a sequence. ${ }^{[36,37]}$ Increased exposure of the esophagus epithelium to refluxed gastric and bile acid, particularly deoxycholic acid, has a critical role in promoting the development of Barrett's esophagus and EAC. NF- $\mathrm{KB}$ is a key regulator of the inflammatory process that has been shown to be activated in EAC. Several studies report that NF- $\mathrm{KB}$ was activated by bile acid components and subsequently involved in the development of metaplasia of Barrett's esophagus and cancer. ${ }^{[25]}$

\section{Gastric Cancer}

Gastric adenocarcinoma is the second leading cause of cancer-related death in the world. ${ }^{[38]} H$. pylori causes chronic gastritis, and the relationship between H. pylori-induced chronic inflammation and cancer is one of the best-elucidated factors. Indeed, $H$. pylori induces active chronic gastric inflammation, which progresses to gastric adenocarcinoma, resulting in approximately 660,000 worldwide new cases of gastric cancer per year. ${ }^{[39]}$ However, only a few percentage of infected persons do develop neoplasia.

Several recent studies described that cytotoxin associated gene A (CagA)-positive H. pylori strains were identified to be particularly carcinogenic. Compared to
CagA-negative strains, H. pylori strains that harbor the CagA pathogenicity islands (PAI) are associated with a significantly increased risk of distal gastric cancer. ${ }^{[40]}$ After attached to gastric epithelial cells, H. pylori CagA-positive strains eject the CagA protein directly into the gastric epithelial cells. After translocation, CagA undergoes tyrosine phosphorylation by Src and Abl kinases and the tyrosine phosphorylated-CagA binds to the Src homology 2 (SHP-2) domain, leading to morphologic alterations such as cell scattering and elongation. ${ }^{[41]}$ Furthermore, CagA-activated SHP-2 deregulates the MAP kinase signaling cascade. ${ }^{[42]}$ The CagA protein of certain H. pylori strains can stimulate expression of IL-8 by activating $\mathrm{NF}-\kappa \mathrm{B},{ }^{[43]}$ thereby contributing to neutrophil infiltration in the gastric mucosa. In addition, chronic inflammation caused by $H$. pylori infection contributes to neoplastic transformation by establishing a positive feedback loop via the signal transducer and activator of transcription (STAT) 3-dependent COX-2 induction, which in turn influences STAT3 regulation via IL-6. ${ }^{[44]}$

Another mechanism of $H$. pylori-induced gastric carcinogenesis is genomic alteration and gene mutation. For example, prevalence of the TP53 mutation in gastric cancer is, on average, approximately $40 \%{ }^{[45]}$ Previous studies have shown that various genetic alterations occur in the gastric mucosa during chronic gastritis, ${ }^{[46,47]}$ suggesting an importance of the accumulated genomic mutations induced by $H$. pylori infection in the development of gastric cancer. Activation-induced cytidine deaminase (AID), a member of the cytidine deaminase family that functions to edit genomic DNA, is an enzyme essential for somatic hypermutation and class-switch recombination in immunoglobulin genes. ${ }^{[48]}$ However, inappropriate AID expression acts as a genomic mutagen to contribute to tumorigenesis. ${ }^{[49,50]}$ Infection with CagA PAI-positive H. pylori ectopically induced high expression of AID via NF- $\mathrm{KB}$ activation in human gastric epithelial cells, leading to multiple mutations in the host genome, such as those found in TP53. The accumulation of nucleotide alterations will lead to the development of gastric cancer. ${ }^{[51]}$

Recently, exciting data showed an association of H. pylori infection with cancer stem cell population. The leucine-rich repeat-containing G-protein coupled receptor (Lgr5) is known as the stem cell marker of GI cancers, including gastric cancer. Lgr5-positive epithelial cells have higher levels of oxidative DNA damage than in Lgr5-negative cells from patients with $H$. pylori-positive gastric cancer, indicating that $H$. pylori specifically targets Lgr5-positive epithelial cells. ${ }^{[52]}$

Other inflammatory risk factors that either act independently of $H$. pylori infection or further enhance its effects have been also identified. For example, chronic gastritis caused by bile reflux can cause intestinal metaplasia as a neoplastic precursor lesion in gastric cancer. Moreover, T-cell-mediated autoimmune 
gastritis fosters the development of intestinal type gastric cancer. ${ }^{[33,54]}$ Thus, these risk factors lead to a state of chronic inflammation and then development of gastric cancer.

\section{Colorectal Cancer}

$\mathrm{CRC}$ is one of the leading causes of cancer-related deaths in the world. CRC is one of the most serious complications of IBD, including ulcerative colitis and Crohn's disease. The relative risk of CRC in patients with colitis is two to eight times higher than the general population. ${ }^{[55]}$ Although it is clear that chronic inflammation is a CRC risk factor, pathogenesis of colitis-associated cancer (CAC) is still uncertain.

CAC develops in chronically inflamed mucosa and is believed to develop in a colitis-dysplasia-carcinoma sequence. The chronic inflammation in IBD often results in increased re-epithelialization of cells and cell turnover in the colonic mucosa and thus, leads to increased risk of errors in DNA repair and cell cycle regulation. Oxidative stress and impaired DNA mismatch repair are combined with proliferation, invasion and angiogenesis, thereby promoting cell growth signaling. In contrast with sporadic CRC, p53 mutations occur in the early stages and APC mutations occur in the late stages of the genesis of CAC. ${ }^{[56,57]}$

Moreover, obesity-related inflammation has been considered to be a plausible link between obesity and cancer. ${ }^{[58]}$ In general, survival of cancer cells is critically dependent on their interaction with neighboring non-malignant cells. ${ }^{[59]}$ The contribution of the tumor stroma to cancer cell survival has been widely studied. The adipocytes surrounding tumor lesions are one of the major components of the tumor stroma. Furthermore, adipose tissue can secrete signaling molecules such as adipocyte-derived cytokines (termed adipokines), pro-inflammatory cytokines, proangiogenic factors and extracellular matrix constituents. ${ }^{[60]}$ From a clinical viewpoint, obese individuals are at an increased risk of developing colon cancer, in addition to the fact that increased adiposity is associated with morbidity and mortality. ${ }^{[58,61]}$ In IBD, many inflammatory cytokines are involved in carcinogenesis, as evidenced by the elevated circulating levels of IL-6 and TNF. TNF is highly elevated in the colon of C57/BL6 mice fed with a high fat diet. ${ }^{[62]}$ Moreover, treatment with TNF-neutralizing monoclonal antibodies decreased growth of colon cancer xenografts and tumor incidence in azoxymethane (carcinogen)-treated leptin-deficient mice. ${ }^{[63]}$ These studies demonstrated that local inflammation mediated by TNF had a key role in tumor initiation in obese rodents.

Most recently, the gut microbiota has been also implicated in the initiation and promotion of CAC. ${ }^{[64,65]}$ It is thought that microbe-driven intestinal inflammation as an etiological factor contributes to CAC development; however, better understanding of the underlying molecular mechanism needs further investigation.

\section{Conclusion}

In this review, we have discussed the links between chronic inflammation and cancer development, with special reference to GI cancers. Future studies will determine the role for this novel anti-inflammation treatment modality in the prevention of GI cancers.

\section{Financial support and sponsorship}

This work was supported by Scientific Research (C) (KAKENHI) (15K10080) from the Japanese Society for the Promotion of Science.

\section{Conflicts of interest}

There are no conflicts of interest.

\section{References}

1. Mantovani A, Allavena P, Sica A, Balkwill F. Cancer-related inflammation. Nature 2008;454:436-44.

2. Macarthur M, Hold GL, El-Omar EM. Inflammation and cancer II. Role of chronic inflammation and cytokine gene polymorphisms in the pathogenesis of gastrointestinal malignancy. Am $J$ Physiol Gastrointest Liver Physiol 2004;286:G515-20.

3. Rasch S, Algul H. A clinical perspective on the role of chronic inflammation in gastrointestinal cancer. Clin Exp Gastroenterol 2014;7:261-72.

4. Pollard JW. Tumour-educated macrophages promote tumour progression and metastasis. Nat Rev Cancer 2004;4:71-8.

5. Qian BZ, Pollard JW. Macrophage diversity enhances tumor progression and metastasis. Cell 2010;141:39-51.

6. Sica A, Allavena P, Mantovani A. Cancer related inflammation: the macrophage connection. Cancer Let 2008;267:204-15.

7. Mantovani A, Sozzani S, Locati M, Allavena P, Sica A. Macrophage polarization: tumor-associated macrophages as a paradigm for polarized M2 mononuclear phagocytes. Trends Immunol 2002;23:549-55.

8. Hull MA, Faluyi OO, Ko CW, Holwell S, Scott DJ, Cuthbert RJ, Poulsom R, Goodlad R, Bonifer C, Markham AF, Coletta PL. Regulation of stromal cell cyclooxygenase-2 in the ApcMin/+ mouse model of intestinal tumorigenesis. Carcinogenesis 2006;27:382-91.

9. Komohara Y, Ohnishi K, Kuratsu J, Takeya M. Possible involvement of the M2 anti-inflammatory macrophage phenotype in growth of human gliomas. $J$ Pathol 2008;216:15-24.

10. Hasita H, Komohara Y, Okabe H, Masuda T, Ohnishi K, Lei XF, Beppu T, Baba H, Takeya M. Significance of alternatively activated macrophages in patients with intrahepatic cholangiocarcinoma. Cancer Sci 2010;101:1913-9.

11. Jaiswal M, LaRusso NF, Burgart LJ, Gores GJ. Inflammatory cytokines induce DNA damage and inhibit DNA repair in cholangiocarcinoma cells by a nitric oxide-dependent mechanism. Cancer Res 2000;60:184-90.

12. Chang CL, Marra G, Chauhan DP, Ha HT, Chang DK, Ricciardiello L, Randolph A, Carethers JM, Boland CR. Oxidative stress inactivates the human DNA mismatch repair system. Am J Physiol Cell Physiol 2002;283:C148-54. 
13. Jaiswal $M$, LaRusso NF, Gores GJ. Nitric oxide in gastrointestinal epithelial cell carcinogenesis: linking inflammation to oncogenesis. Am J Physiol Gastrointest Liver Physiol 2001;281:G626-34.

14. Porta C, Riboldi E, Sica A. Mechanisms linking pathogens-associated inflammation and cancer. Cancer Lett 2011;305:250-62.

15. Wu WK, Sung JJ, Lee CW, Yu J, Cho CH. Cyclooxygenase-2 in tumorigenesis of gastrointestinal cancers: an update on the molecular mechanisms. Cancer Lett 2010;295:7-16.

16. Williams CS, Mann M, DuBois RN. The role of cyclooxygenases in inflammation, cancer, and development. Oncogene 1999;18:7908-16.

17. Liao X, Lochhead P, Nishihara R, Morikawa T, Kuchiba A, Yamauchi M, Imamura Y, Qian ZR, Baba Y, Shima K, Sun R, Nosho K, Meyerhardt JA, Giovannucci E, Fuchs CS, Chan AT, Ogino S. Aspirin use, tumor PIK3CA mutation, and colorectal-cancer survival. $N$ Engl J Med 2012;367:1596-606.

18. Din FV, Theodoratou E, Farrington SM, Tenesa A, Barnetson RA, Cetnarskyj R, Stark L, Porteous ME, Campbell H, Dunlop MG. Effect of aspirin and NSAIDs on risk and survival from colorectal cancer. Gut 2010;59:1670-9.

19. Karin M, Greten FR. NF-kappaB: linking inflammation and immunity to cancer development and progression. Nat Rev Immunol 2005;5:749-59.

20. Chen LW, Egan L, Li ZW, Greten FR, Kagnoff MF, Karin M. The two faces of IKK and NF-kappaB inhibition: prevention of systemic inflammation but increased local injury following intestinal ischemia-reperfusion. Nat Med 2003;9:575-81.

21. Karin M. Nuclear factor-kappaB in cancer development and progression. Nature 2006;441:431-6.

22. Soutto M, Belkhiri A, Piazuelo MB, Schneider BG, Peng D, Jiang A, Washington MK, Kokoye Y, Crowe SE, Zaika A, Correa P, Peek RM Jr, El-Rifai W. Loss of TFF1 is associated with activation of NF-kappaB-mediated inflammation and gastric neoplasia in mice and humans. $J$ Clin Invest 2011;121:1753-67.

23. Barnes PJ, Karin M. Nuclear factor-kappaB: a pivotal transcription factor in chronic inflammatory diseases. N Engl J Med 1997;336:1066-71.

24. Karin M. NF-kappaB and cancer: mechanisms and targets. Mol Carcinog 2006;45:355-61.

25. Huo X, Juergens S, Zhang X, Rezaei D, Yu C, Strauch ED, Wang JY, Cheng E, Meyer F, Wang DH, Zhang Q, Spechler SJ, Souza RF. Deoxycholic acid causes DNA damage while inducing apoptotic resistance through NF-kappaB activation in benign Barrett's epithelial cells. Am J Physiol Gastrointest Liver Physiol 2011;301:G278-86.

26. Naugler WE, Karin M. NF-kappaB and cancer-identifying targets and mechanisms. Curr Opin Genet Dev 2008;18:19-26.

27. Baan R, Straif K, Grosse Y, Secretan B, El Ghissassi F, Bouvard V, Altieri A, Cogliano V; WHO International Agency for Research on Cancer Monograph Working Group. Carcinogenicity of alcoholic beverages. Lancet Oncol 2007;8:292-3.

28. Morita M, Saeki H, Mori M, Kuwano H, Sugimachi K. Risk factors for esophageal cancer and the multiple occurrence of carcinoma in the upper aerodigestive tract. Surgery 2002;131:1-6.

29. Oka D, Yamashita S, Tomioka T, Nakanishi Y, Kato H, Kaminishi M, Ushijima T. The presence of aberrant DNA methylation in noncancerous esophageal mucosae in association with smoking history: a target for risk diagnosis and prevention of esophageal cancers. Cancer 2009;115:3412-26.

30. Shigaki H, Baba Y, Watanabe M, Iwagami S, Miyake K, Ishimoto T, Iwatsuki M, Baba H. LINE-1 hypomethylation in noncancerous esophageal mucosae is associated with smoking history. Ann Surg Oncol 2012;19:4238-43.

31. Brooks PJ, Enoch MA, Goldman D, Li TK, Yokoyama A. The alcohol flushing response: an unrecognized risk factor for esophageal cancer from alcohol consumption. PLoS Med 2009;6:50.

32. Yoshida A, Huang IY, Ikawa M. Molecular abnormality of an inactive aldehyde dehydrogenase variant commonly found in Orientals. Proc Natl Acad Sci U S A 1984;81:258-61.

33. Islami F, Boffetta P, Ren JS, Pedoeim L, Khatib D, Kamangar F. High-temperature beverages and foods and esophageal cancer risk-a systematic review. Int J Cancer 2009;125:491-524.

34. Hardefeldt HA, Cox MR, Eslick GD. Association between human papillomavirus (HPV) and oesophageal squamous cell carcinoma: a meta-analysis. Epidemiol Infect 2014;142:1119-37.

35. Rustgi AK, El-Serag HB. Esophageal carcinoma. $N$ Engl $J$ Med 2014;371:2499-509.

36. Cameron AJ, Ott BJ, Payne WS. The incidence of adenocarcinoma in columnar-lined (Barrett's) esophagus. N Engl J Med 1985;313:857-9.

37. Shaheen NJ, Richter JE. Barrett's oesophagus. Lancet 2009;373:850-61.

38. Polk DB, Peek RM Jr. Helicobacter pylori: gastric cancer and beyond. Nat Rev Cancer 2010;10:403-14.

39. De Martel C, Ferlay J, Franceschi S, Vignat J, Bray F, Forman D, Plummer M. Global burden of cancers attributable to infections in 2008: a review and synthetic analysis. Lancet Oncol 2012;13:607-15.

40. Blaser MJ, Perez-Perez GI, Kleanthous H, Cover TL, Peek RM, Chyou PH, Stemmermann GN, Nomura A. Infection with Helicobacter pylori strains possessing cagA is associated with an increased risk of developing adenocarcinoma of the stomach. Cancer Res 1995;55:2111-5.

41. Higashi H, Tsutsumi R, Muto S, Sugiyama T, Azuma T, Asaka M, Hatakeyama M. SHP-2 tyrosine phosphatase as an intracellular target of Helicobacter pylori CagA protein. Science 2002;295:683-6.

42. Saadat I, Higashi H, Obuse C, Umeda M, Murata-Kamiya N, Saito Y, Lu H, Ohnishi N, Azuma T, Suzuki A, Ohno S, Hatakeyama M. Helicobacter pylori CagA targets PAR1/MARK kinase to disrupt epithelial cell polarity. Nature 2007;447:330-3.

43. Brandt S, Kwok T, Hartig R, König W, Backert S. NF-kappaB activation and potentiation of proinflammatory responses by the Helicobacter pylori CagA protein. Proc Natl Acad Sci U S A 2005;102:9300-5.

44. Xiong H, Du W, Sun TT, Lin YW, Wang JL, Hong J, Fang JY. A positive feedback loop between STAT3 and cyclooxygenase-2 gene may contribute to Helicobacter pylori-associated human gastric tumorigenesis. Int $J$ Cancer 2014;134:2030-40.

45. Fenoglio-Preiser CM, Wang J, Stemmermann GN, Noffsinger A. TP53 and gastric carcinoma: a review. Hum Mutat 2003;21:258-70

46. Stock M, Otto F. Gene deregulation in gastric cancer. Gene 2005;360:1-19.

47. Morgan C, Jenkins GJ, Ashton T, Griffiths AP, Baxter JN, Parry EM, Parry JM. Detection of p53 mutations in precancerous gastric tissue. Br J Cancer 2003;89:1314-9.

48. Honjo T, Kinoshita K, Muramatsu M. Molecular mechanism of class switch recombination: linkage with somatic hypermutation. Annu Rev Immunol 2002;20:165-96.

49. Cascalho M. Advantages and disadvantages of cytidine deamination. J Immunol 2004;172:6513-8.

50. Kinoshita K, Nonaka T. The dark side of activation-induced 
cytidine deaminase: relationship with leukemia and beyond. Int J Hematol 2006;83:201-7.

51. Matsumoto Y, Marusawa H, Kinoshita K, Endo Y, Kou T, Morisawa T, Azuma T, Okazaki IM, Honjo T, Chiba T. Helicobacter pylori infection triggers aberrant expression of activation-induced cytidine deaminase in gastric epithelium. Nat Med 2007;13:470-6.

52. Uehara T, Ma D, Yao Y, Lynch JP, Morales K, Ziober A, Feldman M, Ota H, Sepulveda AR. H. pylori infection is associated with DNA damage of Lgr5-positive epithelial stem cells in the stomach of patients with gastric cancer. Dig Dis Sci 2013;58:140-9.

53. Sobala GM, O'Connor HJ, Dewar EP, King RF, Axon AT, Dixon MF. Bile reflux and intestinal metaplasia in gastric mucosa. J Clin Pathol 1993;46:235-40.

54. Nguyen TL, Khurana SS, Bellone CJ, Capoccia BJ, Sagartz JE, Kesman RA Jr, Mills JC, DiPaolo RJ. Autoimmune gastritis mediated by $\mathrm{CD} 4+\mathrm{T}$ cells promotes the development of gastric cancer. Cancer Res 2013;73:2117-26.

55. Chambers WM, Warren BF, Jewell DP, McC Mortensen NJ. Cancer surveillance in ulcerative colitis. $\mathrm{Br} \quad J \quad$ Surg 2005;92:928-36.

56. Rogler G. Chronic ulcerative colitis and colorectal cancer. Cancer Lett 2014;345:235-41.

57. Ullman TA, Itzkowitz SH. Intestinal inflammation and cancer. Gastroenterology 2011;140:1807-16.

58. Park J, Euhus DM, Scherer PE. Paracrine and endocrine effects of adipose tissue on cancer development and progression. Endocr Rev 2011;32:550-70.

59. Hanahan D, Weinberg RA. Hallmarks of cancer: the next generation. Cell 2011;144:646-74.

60. Park J, Morley TS, Kim M, Clegg DJ, Scherer PE. Obesity and cancer-mechanisms underlying tumour progression and recurrence. Nat Rev Endocrinol 2014;10:455-65.

61. Parekh N, Chandran U, Bandera EV. Obesity in cancer survival. Annu Rev Nutr 2012;32:311-42.

62. Liu Z, Brooks RS, Ciappio ED, Kim SJ, Crott JW, Bennett G, Greenberg AS, Mason JB. Diet-induced obesity elevates colonic TNF-alpha in mice and is accompanied by an activation of Wnt signaling: a mechanism for obesity-associated colorectal cancer. J Nutr Biochem 2012;23:1207-13.

63. Flores MB, Rocha GZ, Damas-Souza DM, Osório-Costa F, Dias MM, Ropelle ER, Camargo JA, de Carvalho RB, Carvalho HF, Saad MJ, Carvalheira JB. Obesity-induced increase in tumor necrosis factor-alpha leads to development of colon cancer in mice. Gastroenterology 2012;143:741-53.

64. Kostic AD, Chun E, Robertson L, Glickman JN, Gallini CA, Michaud M, Clancy TE, Chung DC, Lochhead P, Hold GL, El-Omar EM, Brenner D, Fuchs CS, Meyerson M, Garrett WS. Fusobacteriumnucleatum potentiates intestinal tumorigenesis and modulates the tumor-immune microenvironment Cell Host Microbe 2013;14:207-15.

65. Irrazábal T, Belcheva A, Girardin SE, Martin A, Philpott DJ. The multifaceted role of the intestinal microbiota in colon cancer. Mol Cell 2014;54:309-20. 